increase of the disease at this time. Dryness-a great promotor of health-here, where a crowded population lives over sewers and its own excreta, becomes a source of disease. Water is now abundant and freely distributed, and should be made to do what rain has not effected.

For the mitigation of the disease and the prevention of pitting I have long practised, and found most successful, the following simple treatment. The rigor which is most marked may be suspected to be the access of this disease, if there exist no local malady to which to attribute it. When this rigor occurs, the patient ought to go to bed and be covered with warm but light clothing; the hands and face ought to be carefully covered, leaving breathing room only to the mouth and noztrils; he ought to get frequent and abundant warm diluentswhey is the best, being akin to the blood, is easily assimilated, and sustains the system against the impending prostration. Nitrate of potass is most effective as a vascular sedative, diaphoretic and depurative, and I combine with it ipecacuanha, aromatic spirits of ammonia, and sometimes squills, thereby improving its efficacy and directing its action to the skin and the kidneys. This treatment, with one full action of an ape. rient, produces diaphoresis of the body and of the hands and face (which must not be checked by allowing the patient to get from under the clothes for any purpose whatever), and reduces the primary fever, always so severe; the increased natural discharge from the skin leaving less for the morbid action to do, the eruption will be less. There are two reasons why the eruption is greatest on the hands and on the face-because these parts are more highly organized, and because they are left uncovered, the rest of the body being covered. The hands, then, must be kept under the bedclothes, and the face covered with cotton-wool, merino, silk, or some warm light mask, leaving only breathing.room. This will cause these parts to perspire like the rest of the body, save the eyes, render the vesicles fewer and smaller and rarely confluent, attended with less inflammation and inflamed areolæ; it will prevent long suffering, mitigate secondary fever, and prevent the red marks or areolæ which disfigure the face for months after recovery. The vesicles or pustules are to be transfixed with a needle, and the matter allowed to escape. The pressure of this lymph, the lower stratum of which is solid, on the fine unprotected papillæ of the cutis, causes the absorption or ulceration, and so makes the pits or marks. This will prevent the pitting. Animal broths should be given for diet

There are many remedies recommended, general and local. $I$ give what I have proved to be successful in this and other climates.

Thurloe-square, May, 1863

\section{THE LARYNGEAL ECRASEUR FOR THE REMOVAL OF SMALL TUMOURS FROM THE INTERIOR OF THE LARYNX.}

By GEORGE D. GIBB, M.D., M.R.C.P., PHXSICIAN TO THB WEST LONDON HOSPITAL.

Now that the diagnosis of many hitherto obscure affections of the larynx has been rendered comparatively easy and clear since the introduction of the laryngoscope, the treatment will become equally so when proper means are at hand to carry it out. In the course of my experience I have had to contrive various instruments for introduction within the larynx to effect particular objects. Some of these are, a large camel's or squirrel's hair brush on whalebone, a scarificator for cdema of the glottis, a laryngeal fluid pulverizer with platinum capsule, and an instrument for the removal of growths or polypi. The last I have called a laryngeal écraseur, from the manner in which it acts. My present communication is to say a few words about it alone.

In 1862, after making the diagnosis of a polypoid tumour attached to the vocal cords of a gentleman who had been hoarse and aphonic for twelve years, and who had undergone all manner of treatment during that time, the observation was made to me that it was satisfactory at least to be told the nature of one's complaint ; but that now that it was known, he should like to get rid of it. Reflecting upon the matter very carefully for a few days, I arranged the principle of an instrument which would remove smali tumours by means of a loop of wire to be drawn home on catching the pedicle. Messrs. Weiss and Son most ably seconded my efforts, and at once comprea hended the nature of what I so much desired.

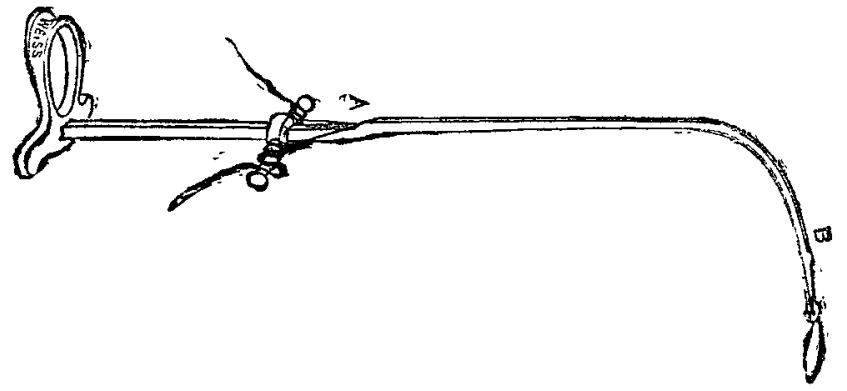

I had carefully experimented on the dead larynx and tongue to get the requisite amount of curvature, so that the moment the instrument should be introduced in to the living larynx, the end of the curve in connexion with the loop of wire should reach the hollow in the thyroid cartilage corresponding to the pomum Adami at the root of the epiglottis and origin of the true vocal cords. This I took most particular pains to ascertain with great accuracy, and then tried it on the dead body with complete success. The instrument was made, and is represented in the accompanying woodcut. It consists of a small square bar, with a ring attached to one end (for the thumb), and terminating at the other in a curved stem, which is grooved on its upper or convex surface to within half an inch of the point. The latter has two small holes drilled in a line with the groove. A cross piece slides on the bar, against which the fore and middle fingers rest. A fine steel wire is passed through the holes of the point (so as to make a loop), carried along the groove, passed through the little holes of the cross-piece, and then wound round it two or three times. On introduction the loop of wire catches the laryngeal tumour like a noose; it is drawn home, the pedicle is cut across, and the tumour is detached. The instrument in its action is not unlike that of Wilde's snare, but it is considerably modified to suit the requirements of the larynx.

The laryngeal écraseur, as figured, I used three or four times, but have since modified it with advantage in turning the crosspiece of movable steel at right angles to the curve of the instrument. The white metal ring has been removed, and one of steel substituted, placed in the same plane as the curve of the limb. This has permitted of very ready application, more so than in the first contrivance.

This écraseur I have now used with success in removing polypi in seven cases. Lest it might be supposed, however, that all tumours require removal by operation, I may mention that in a number where the base was large, or the situation inconvenient, they have been dissipated by topical applications made every few days for a certain time.

I was not unmindful of the instruments used on the Continent for the removal of polypi from the larynx; but how they could be introduced with their enormous curve, like a lithotomy sound, was to me an enigma. Moreover, none possessed the simplicity of my own.

Portman-street, Portman-square, A pril, 1863.

St. Bartholomew's Hospital. - From some very interesting and laborious statistical tables, compiled with great care by Dr. Edwards, one of the physicians to the hospital, it appears that the number of patients under treatment during the past year amounted to 5911 , of which number no less than 4371 were discharged cured and relieved, 236 being discharged unrelieved, and for other than medical reasons there were 218. Of the 605 who died, it is deserving of mention that 88 , or 14.54 per cent., died within twenty-four hours of admission into the hospital. Table XII. is a very elaborate affair, ex. hibiting the whole number of cases under treatment, with the average mortality for each disease during the years 1860,1861 , and 1862 respectively. These tables will be found of great value.

Mortality In the Prisons of Scotland.-In the general prison for Scotland, the total prison population for twenty-one years, 1842-62, was 17,541; the sum of the daily average population was 9481 , and the number of deaths was 144 , being at the average rate of 1.51 per ceot. per annum, or about 15 per 1000 prisoners. In the local prisons of Scotland, with an average daily population of 46,095 , the number of deaths annually, for a period of eighteen years, 1844-61, was 547 , being $1 \cdot 1$ per cent., or 11 deaths for every 1000 prisoners. This statement is exclusive of those prisoners who were released on medical grounds. 